\title{
Evaluation of TMO's (Turkish Grain Board) Appointment System for Procurement
}

\author{
Gursel Kusek*, Metin Turker**, Sinasi Akdemir***, Seyit Hayran ${ }^{\star \star \star}$
}

DOI: $10.30682 / \mathrm{nm} 1801 \mathrm{e}$

JEL classification: A11, L11

\begin{abstract}
This study was conducted in the Konya province, which is one of the most important grain production centers of Turkey. The primary data was obtained by questionnaires that were given out to 54 producers. The main purpose of this study is investigating the effects of TMO's "Appointment System for Procurement (ASP)" on marketing structure of wheat and the decision-making process of farmers.

Some general characteristics of the sample farms are as follows; (1) 93\% of enterprises are registered to Farmer Register System, (2) registration rate increases as size of enterprises increases, (3) property and land rate (61\%) decreases as size of enterprises increases, (4) average parcel number is 8.8, (5) maturity level of product is taken into consideration while determining harvest season of wheat, (6) availability of combine harvester is also an important factor, (7) 77\% of producers are not encountering harvest problem, (8) $61 \%$ of them sell their products through appointment system of TMO and (9) 36\% of them change appointment dates. As a result of factor analysis, we determined 5 factors explaining 79\% of the total variance for product marketing condition of producers. The weekend holiday of TMO, small and fragmented parcels and also difficulties in finding combine harvester and in turn problems caused by FRS limitation constitute the first factor. The size of Enterprises was the second factor, the age and education level of producers which is effective in adapting to the appointment system was the third factor. Also, the determination of sale price and institution/person of product was the fourth factor, while the credit-finance structure of the enterprise constituted the fifth factor.
\end{abstract}

Keywords: TMO, Appointment System for Procurement (ASP), Konya, Wheat, Factor Analysis.

\section{Introduction}

Offering products to the market in a healthy way in accordance with demand condition is an important dimension of the production process as well as productivity and quality in agricultural production. In this respect, marketing is one of the important branches of agricultural enterprises. Farmers' in- come can be increased by an effective marketing system which will provide an important contribution to increasing producers' welfare, wealth and life quality.

In the agricultural market of Turkey, there are different actors playing their respective roles such as the state and cooperatives on one hand and the

\footnotetext{
* General Director of Agricultural Reform, Republic of Turkey Ministry of Food, Agriculture and Livestock, Ankara, Turkey. ** Deputy General Director of Agricultural Reform, Republic of Turkey Ministry of Food Agriculture, and Livestock, Ankara, Turkey.

*** Cukurova University, Faculty of Agriculture, Department of Agricultural Economics, Adana, Turkey.

Corresponding author: sinasi.akdemir@gmail.com.
} 
private sector on the other hand, although it changes according to product groups. The public sector plays an important role in the marketing of some products, particularly grains and tea. Due to both its importance in meeting the food needs of societies and food crises caused by global climate change, grain production and marketing has gained a special importance recently. The volatility of agricultural product prices will increasingly continue and first of all wheat and then other products will be affected by this and the prices of wheat, maize and skimmed milk powder will increase at a rate of $40-60 \%$ (KB, 2014).

Grains have a special place in the economy of the country. Thus, Turkey takes place near the top in the world in terms of production, consumption, and trade of grains. Considering the share of Turkey in grain production between 1979 and 2003 as five year period, it is seen that the average rate is $3.5 \%$ (Demirbas et al., 2005). According to the data in 2014, grain has been planted on $66 \%$ of the cultivation areas in the country and wheat on $68 \%$ of it. Grain production in the country has approached 31 million tons and 62\% (19 million tons) of this production is wheat (TÜIK, 2015).

Although wheat is so important to Turkey; there are problems in marketing of wheat due to climate conditions, different harvest periods, limited marketing opportunities and price fluctuations both from year to year and also within a year. The Turkish Grain Boards (TMO) and private sector all play a role in the marketing of wheat in the country. Wheat amount procured by TMO varies by the years. In the case of a decrease in price especially during the harvest period due to overproduction/ or immediate supply, TMO procurement amount increases, so as to prevent extreme decreases in prices and protect the producers. Also, in the event that prices are higher than expected market prices, TMO decreases procured amount, prevents extreme increases in market prices and so protects the consumers.

Other previous studies have revealed that if TMO doesn't procure, producers sell their products, mostly (94.4\%) to tradesmen (Y1lmaz, 2010). Over the last twenty-five years, the TMO procurement ratio in total production is the highest in 2013 with $25.8 \%$ and this ratio is $9 \%$ in 2013 while the appointment system is in practice (TMO, 2014).
The initial time of wheat harvest varies by regions. Harvest start first in the south regions (Cukurova) in the first days of June. Thrace and Central Anatolia regions come after Cukurova (July) and the harvest period ends in Eastern Anatolia in August (Süzer, 2014). Harvest is carried out in a limited period of 20 days in each region. The shortness of the harvest period and the desire of producers in the same region to offer their products to the market immediately after harvest in a very short period cause big problems. The most important reasons for this are both meeting the production costs met by loan and domestic needs in the production year and their desire to harvest their products without suffering any damage caused by natural disasters such as fire, hail, flood, etc. As a result, producers have problems in marketing their products during the harvest period. Another important factor causing these problems is the institutions and agencies related to wheat marketing.

The price of wheat increases during the harvest period in relation to production amount because of the limited harvest period, lack of storage opportunities for producers and producers' desire to meet their needs as soon as possible, but after a few months following the harvest period prices increase. There is a risk of forwarding sales to other actors other TMO, the risk of extension of terms from 15-20 days to 2-3 months and the risk of non-payment on time. Therefore, most of the producers prefer to sell their products to TMO even if the price is lower than the market price.

Since harvest begins at the same time in a region and in response to this slow performance of TMO procurement due to bureaucratic structure, there have been long queues in front of the TMO in recent years. This has led on the one hand to the increase in transportation cost due to the long waiting periods and difficulties in finding new vehicles and on the other hand producers' selling their products to tradesmen at a lower price and also the long payment terms. In order to prevent these problems for producers, to provide more quality service to producers and to realize procurement as soon as possible in the harvest period, TMO has begun to realize cash purchases through an appointment system or without appointment system and procurement as consignee through an appointment system. Since 2012, producers who make an appointment for sale 
to the TMO have realized their sales on the same day and producers who have not made an appointment to have realized their sales according to queue in front of TMO. Under this system, producers can make appointments to sell or to consign their wheat through the website of TMO www.tmo.gov.tr or rendevu.tmo.gov.tr and through TMO branch offices or agency directorates. The aims of this system are to minimize producers' waiting in front of TMO regional purchase office/centers, to enable producers to carry out the harvest and transportation of their products and to prevent producers from paying additional transportation fee (since they deliver their products on the day of appointment).

The maximum product amount that a producer can sell to TMO through Appointment System (ASP) is determined as amount foreseen by the ministry according to the cultivation area registered to Farmer Register System. Producers make their appointments for this production amount (at least 5 ton) according to the day on which they sell and the amount which they sell. Producers can change their appointments in a maximum of twice. In the case of more appointment changes, they can not utilize from the appointment system (TMO, 2014). As of 2013, 9\% (1.985.646 ton wheat) of 22 million ton production had been realized through ASP by TMO (TMO, 2014).

Some problems are encountered from time to time under the Appointment system. We can say that these problems are caused by many factors such as difficulties in finding combine harvester, non-performance of harvest in a planned way, early or late maturation of the product due to seasonal and daily changes in climate, fluctuation in productivity. Hence, some problems have occurred, such as producers' having difficulty in making appointments and because of this reason they wait for harvest, preferring to sell their products to tradesmen at less price with the consideration of inability to make an appointment.

It is very important to examine the possible effects of ASP on producers' decision in order to determine the problems faced during the marketing of wheat. Research has been carried out both for determining problems of producers and for revealing data that will help to solve problems faced during implementation by actors playing role in marketing. In this study change occurring in wheat sales after TMO's transition to the appointment system in Konya, which meets $11 \%$ of procured wheat under ASP, impacts of ASP, problems caused by ASP and views of farmers on this system have been examined.

\section{Materials and Method}

The data obtained from questionnaires filled with face to face interviews with producers in Konya which is one of the leading cities in grain production in the Central Anatolian Region constitutes the main data of this research.

Konya is one of the major grain centers of Turkey. The share of wheat in the economy of the region has remained high historically due to the fact that the climatic conditions are favorable and the industrial facilities in the region operate in sectors based on wheat. Around $9.8 \%$ of the total cultivated area in Turkey lies within the borders of Konya. In line with this characteristic, also the highest wheat production is realized in Konya. About 73\% of wheat cultivated in the province is bread wheat and $27 \%$ is durum wheat. The province is the largest area in terms of wheat cultivation in Turkey with 0.75 million hectares. The annual cereal production in Konya is about 4.5 million metric ton. Approximately 2.2 million tons of this production is wheat. Wheat production in Konya has been increasing, in 2000, the wheat production in Konya was 1.8 million ton, in 2011 this amount was 1.8 million tons and it has decreased to 1.7 million tons in 2012 (KTB, 2014).

Approximately 213 thousand tons (13\%) of 1.7 million tons of wheat produced in Konya in 2013 was sold to TMO through ASP. Under the research, 54 questionnaires have been filled by agricultural enterprises in Karatay, Cumra and Cihanbeyli towns of Konya in 2014 (for the 2013 production period).

In the said the questionnaires in order to determine problems faced under ASP and factors affecting them, questions on the size of enterprises, socio-economic structures of entrepreneurs, their information level on the system, problems they face and their attitudes against these problems and their views about the system were asked. Results of the research were analyzed according to the size of enterprises (enterprises having 1-170 da land are grouped as small, enterprises having 171-350 da 
land as medium and enterprises having 351 da and more land as large) and elements that are effective in the evaluation of ASP were determined through factor analysis which is one of statistical analysis techniques reducing many interrelated variables into a few factors (Akgül and Çevik, 2003; Tatlidil 2002; Akdemir, 1994).

\section{Research Findings}

According to descriptive statistics of the survey data, the average age of entrepreneurs is 48 , their average experience duration in agriculture is 25 years, the size of their household is 5.2, while $73 \%$ of them had received secondary school education or less education, $14 \%$ of them had graduated from faculty or college (Tables 1 and 2).

It can be seen that $64 \%$ of entrepreneurs use credit and the rate of using credit increases as the size of enterprises increases. It is determined that public banks are preferred as credit resource and $40 \%$ of entrepreneurs prefer to get credit from public banks. Also, it is revealed that animal rising (51\%) is carried out in enterprises as well as crop production and the rate of realizing livestock decreases as the size of enterprises increase (Table 3).

It is assessed that $93 \%$ of entrepreneurs are registered to the Farmer Register System and

Table 1 - General Features of Entrepreneurs.

\begin{tabular}{|l|c|c|c|}
\hline \multicolumn{1}{|c|}{ Size of Enterprises } & $\begin{array}{c}\text { Age of Entrepreneur } \\
\text { (Year) }\end{array}$ & $\begin{array}{c}\text { Size of Family } \\
\text { (Number) }\end{array}$ & $\begin{array}{c}\text { Experience Duration } \\
\text { (Year) }\end{array}$ \\
\hline Small & 46 & 4,6 & 21 \\
\hline Medium & 50 & 5,5 & 27 \\
\hline Large & 47 & 5,5 & 24 \\
\hline Average & 48 & 5,2 & 25 \\
\hline
\end{tabular}

Table 2 - Education Level of Entrepreneurs.

\begin{tabular}{|l|c|c|c|c|c|c|}
\hline \multirow{2}{*}{ Size of Enterprises } & \multicolumn{7}{|c|}{ Level of Education (\%) } \\
\cline { 2 - 7 } & $\begin{array}{c}\text { Primary } \\
\text { School }\end{array}$ & $\begin{array}{c}\text { Secondary } \\
\text { School }\end{array}$ & $\begin{array}{c}\text { High } \\
\text { School }\end{array}$ & Faculty & Postgraduate & Total \\
\hline Small & 67 & 7 & 6 & 20 & 0 & 100 \\
\hline Medium & 70 & 4 & 18 & 4 & 4 & 100 \\
\hline Large & 62 & 8 & 15 & 15 & 0 & 100 \\
\hline Average & 67 & 6 & 13 & 12 & 2 & 100 \\
\hline
\end{tabular}

the rate of being registered increases as the size of enterprises increases. In terms of possession, it is determined that $61 \%$ of agricultural lands are properties of the entrepreneurs, $19 \%$ of them

Table 3 - Information on Credit Using and Animal Breeding in Enterprises (\%).

\begin{tabular}{|l|c|c|c|c|}
\hline \multirow{2}{*}{$\begin{array}{c}\text { Size of } \\
\text { Enterprises }\end{array}$} & \multicolumn{2}{|c|}{ Credit Using } & \multicolumn{2}{c|}{ Animal Breeding } \\
\cline { 2 - 5 } & Yes & No & Yes & No \\
\hline Small & 69 & 31 & 54 & 46 \\
\hline Medium & 58 & 42 & 56 & 44 \\
\hline Large & 70 & 30 & 38 & 62 \\
\hline Average & 64 & 36 & 51 & 49 \\
\hline
\end{tabular}

are rent, $17 \%$ share-cropping and 3\% belong to the treasury. Land ownership decreases as the size of enterprises increases while the rent and share-cropping increases as the size of enterprises increase. The average parcel number of enterprises is calculated as 8.8 and this number increases as the size of enterprises increase and the area on which wheat is cultivated decreases as the size of enterprises increases (Table 4).

In terms of the method of selling products, it is understood that producers first of all search and learn the market price of products and then they bargain with the purchaser and realize sales (Table 5). 
Table 4 - Land Possession of Enterprises.

\begin{tabular}{|l|c|c|c|c|c|c|c|c|c|c|}
\hline \multirow{2}{*}{$\begin{array}{c}\text { Size of } \\
\text { Enterprise }\end{array}$} & Enterprise & \multicolumn{5}{|c|}{ Possession (\%) } & & $\begin{array}{c}\text { Area } \\
\text { Registered } \\
\text { to FRS(\%) }\end{array}$ & $\begin{array}{c}\text { No of } \\
\text { Parcels } \\
\text { (No) }\end{array}$ & $\begin{array}{c}\text { Wheat } \\
\text { Cultivated } \\
\text { Area (\%) }\end{array}$ \\
\cline { 2 - 10 } Small & 16 & 30 & 68 & 16 & 7 & 9 & 100 & 99 & 3,6 & 85 \\
\hline Medium & 24 & 44 & 62 & 18 & 19 & 1 & 100 & 85 & 7,5 & 59 \\
\hline Large & 14 & 26 & 51 & 24 & 25 & - & 100 & 37 & 16,8 & 37 \\
\hline Average & 54 & 100 & 61 & 19 & 17 & 3 & 100 & 61 & 8,8 & 51 \\
\hline
\end{tabular}

Table 5 - Determination of Sale Price of Product.

\begin{tabular}{|c|c|c|c|c|}
\hline \multirow{2}{*}{$\begin{array}{c}\text { Size of } \\
\text { Enterprise }\end{array}$} & \multicolumn{4}{|c|}{ Determination of Sale Price of Product (\%) } \\
\hline & $\begin{array}{l}\text { Acceptance of Price Of- } \\
\text { fered by the Purchaser }\end{array}$ & $\begin{array}{l}\text { First of all learning market price, } \\
\text { then selling at the highest price }\end{array}$ & $\begin{array}{l}\text { Sale by bargaining } \\
\text { with the purchaser }\end{array}$ & Total \\
\hline Small & 12 & 41 & 47 & 100 \\
\hline Medium & 4 & 61 & 36 & 100 \\
\hline Large & - & 43 & 57 & 100 \\
\hline Average & 5 & 48 & 47 & 100 \\
\hline
\end{tabular}

Producers determine the price of the product by asking, especially the tradesmen. Such that, they take the first product obtained from production at the beginning of the harvest to the tradesman in the region and they bargain on this sample. Information such as a region of product and amount to be delivered is provided during bargaining. The tradesman submits a quote by considering the variety of the product, moisture situation, the amount of foreign matters and the amount of cracked wheat and even the rate of protein and starch (Table 6).

While determining the selling area and in turn price of the product, payment time, trust of buyers and also the amount and quality of product become influential variables. It is found that the payment time and trust to buyers is important for the determination of the price for producers (Table 7).
Thus, previous researches confirm these findings. Research results suggest that $\mathrm{N} \%$ of producers buy their inputs at high prices and this accounts to shortage of cash, they arrange a due date taking harvest period into consideration and so they prefer cash sale; the high price and trust to buyer become important at that point and most of the producers prefer to sell their products to TMO since it is a state trading enterprise (Karabak et al., 2013).

While determining the harvest time of the product, first of all, the maturity of the product is taken into consideration. In addition to this, finding or not finding available combine harvester is another factor for the early or late harvest of the product. From time to time, concerns about the inability to find a combine harvester cause early harvest of the product which causes important problems in the product sale. This, therefore, brings a situation in

Table 6 - Resource for Learning Market Price of Product in Sale Period.

\begin{tabular}{|l|c|c|c|c|}
\hline \multirow{2}{*}{ Size of Enterprise } & \multicolumn{3}{|c|}{ Resource for Learning Market Price (\%) } \\
\cline { 2 - 5 } & Visiting Market Regularly & From Friends and Contacts & From Tradesman & Total \\
\hline Small & - & 24 & 76 & 100 \\
\hline Medium & 7 & 18 & 75 & 100 \\
\hline Large & - & 12 & 88 & 100 \\
\hline Average & 3 & 18 & 79 & 100 \\
\hline
\end{tabular}


Table 7 - Factors taken into account while determining institution/person to which Product is sold and Price of Product.

\begin{tabular}{|l|c|c|c|c|c|}
\hline \multirow{2}{*}{ Size of Enterprise } & \multicolumn{5}{|c|}{ Factors Being Effective in Determining Price (\%) } \\
\cline { 2 - 6 } & Time of Payment & Trust to Buyer & Amount of Product & Quality of Product & Total \\
\hline Small & 36 & 9 & 13 & 42 & 100 \\
\hline Medium & 35 & 16 & 16 & 33 & 100 \\
\hline Large & 29 & 4 & 17 & 50 & 100 \\
\hline Average & 34 & 11 & 16 & 39 & 100 \\
\hline
\end{tabular}

Table 8 - Factors that determine Harvest Time.

\begin{tabular}{|l|c|c|c|c|c|}
\hline \multirow{2}{*}{ Size of Enterprise } & \multicolumn{5}{|c|}{ Factors that Determine Harvest Time (\%) } \\
\cline { 2 - 6 } & $\begin{array}{c}\text { Maturity } \\
\text { of Product }\end{array}$ & $\begin{array}{c}\text { Appointment } \\
\text { with TMO }\end{array}$ & $\begin{array}{c}\text { Availability of } \\
\text { Combine Harvester }\end{array}$ & Other & Total \\
\hline Small & 55 & 5 & 37 & 3 & 100 \\
\hline Medium & 40 & 13 & 42 & 5 & 100 \\
\hline Large & 67 & 0 & 23 & 10 & 100 \\
\hline Average & 51 & 7 & 36 & 6 & 100 \\
\hline
\end{tabular}

which a wet product is dried in the garden of the farm for days. This leads both to transportation and labor costs and the product going bad (Table 8). Also, it is stated that there is grain loss to a great extent during late harvest and it is recommended that the moisture ratio of wheat should be less than $12 \%$ for secure storage/marketing (Süzer, 2014).

About $77 \%$ of producers state that they do not meet any problem during harvest. Although it varies by the size of enterprises, $61 \%$ of producers $(51-71 \%)$ sell their products through an appointment system. In terms of institution/person to which product is sold, $55 \%$ of producers sell their products to TMO and $45 \%$ to tradesmen. As the size of enterprises increase, the ratio of selling product to TMO increases (Table 9). Under another research performed in the Central Anatolian Region, it was determined that $58 \%$ of producers sell their wheat to tradesmen (Karabak et al., 2013). This is because the appointment system has been applied for the first time and decrease in harvest due to drought has caused an increase in the market price of the product. Hence, researches state that it takes time for producers to adapt new applications (Küçükongar et al., 2014).

Even if just a few, some of the producers who have problems in making appointment sell their
Table 9 - Purchaser to whom Producers sell their Products (\%).

\begin{tabular}{|l|c|c|c|}
\hline $\begin{array}{c}\text { Size of } \\
\text { Enterprise }\end{array}$ & TMO & Tradesmen & Total \\
\hline Small & 48 & 52 & 100 \\
\hline Medium & 52 & 48 & 100 \\
\hline Large & 64 & 36 & 100 \\
\hline Average & 55 & 45 & 100 \\
\hline
\end{tabular}

products to tradesmen at a low price or they delay harvest or keep their product in the storehouse (Table 10).

It is observed that producers make their appointments according to the maturation period of the product, but it is inevitable to move the appointment to an earlier time or delay due to the fact that climate conditions occur in a different way from the expected. The rate of producers who change their appointment dates is $36 \%$.

There are producers reporting that transportation cost increases because of extra transportation services since they sometimes take their product to TMO through two services due to delays and breakdowns in a combine harvester and inability to get efficiency from the product. Flexibility in appointment dates (ensuring, for example, one 
Table 10 - Problems occurred in Appointment System for Procurement.

\begin{tabular}{|l|c|c|c|c|c|c|c|c|}
\hline \multirow{2}{*}{$\begin{array}{c}\text { Size of } \\
\text { Enterprise }\end{array}$} & \multicolumn{2}{|c|}{$\begin{array}{c}\text { Changing } \\
\text { Appointment } \\
\text { Date (\%) }\end{array}$} & \multicolumn{2}{c|}{$\begin{array}{c}\text { Increase in } \\
\text { Transportation Costs } \\
(\%)\end{array}$} & \multicolumn{2}{c|}{$\begin{array}{c}\text { Inability to Realize } \\
\text { Selling to TMO due to } \\
\text { Late Maturation (\%) }\end{array}$} & \multicolumn{2}{c|}{$\begin{array}{c}\text { Having Problems } \\
\text { due to Cancel of } \\
\text { Appointments (\%) }\end{array}$} \\
\cline { 2 - 9 } & Yes & No & Yes & No & Yes & No & Yes & No \\
\hline Small & 20 & 80 & 27 & 73 & 31 & 69 & 20 & 80 \\
\hline Medium & 54 & 46 & 46 & 54 & 21 & 79 & 33 & 67 \\
\hline Large & 21 & 79 & 21 & 79 & 52 & 48 & 0 & 100 \\
\hline Average & 36 & 64 & 34 & 64 & 38 & 62 & 21 & 79 \\
\hline
\end{tabular}

day flexibility in appointment date) would prevent this unnecessary cost. However, the producers explain that this cost is so little to compare with the high cost caused by waiting for a few days in the queue in the previous years. There are producers who express that they cannot sell their products to TMO since their products ripen later than the expected period. This is mostly because some producers have large areas and in turn, they have a strong bargaining power, so they easily turn toward tradesmen when they have a little problem in selling their products to TMO. But, these producers don't have a problem when they cancel their appointment, unlike small enterprises. Under the study realized by (Y1ldiz et al., 2013) it is seen that farmers having 10 hectares or more area pay more attention to marketing factors to sell product supply in order to increase production compared to farmers having less area.

Producers express that they have problems in finding combine harvester in a timely manner and to bring it to their lands due to scattered and small land ownership and also they have problems since combine harvester is not brought on the pre-determined date. However, these problems decrease depending on the size of enterprises. Producers have problems in selling some products because of FRS limitation. This increases as the size of enterprises increase. Some farmers report that they have problems in selling some of their products since they have more products than stated under FRS due to the fact that they obtain product from rented or jointly cultivated areas or areas with collective ownership. Since the harvest period in each region is short and combine harvester operators want to work in weekends when farmers who have large areas harvest their product in Saturday afternoons, they have to wait on Sunday for selling their products to TMO or they sell their products to tradesmen. There can be accumulated on Mondays because products harvested on Saturday are transported on Sundays and line up with products harvested on Sundays.

Producers transport their products by their tractors or truck. Some producers in the region have 5-9 ton trailers and also they take trailers from their neighbor and they transport their products by hitching these trailers (2-3) to their tractors. Trucks are generally rented for transportation. It is seen that finding trucks for transportation can be a problem for producers due to the high demand for trucks during the harvest period and workload of trucks con-

Table 11 - Availability of Combine Harvester, FRS Limitation and Sunday Holiday of TMO.

\begin{tabular}{|l|c|c|c|c|c|c|c|c|}
\hline \multirow{2}{*}{$\begin{array}{c}\text { Size of } \\
\text { Enterprise }\end{array}$} & $\begin{array}{c}\text { Unavailability of Combine } \\
\text { Harvester due to Scattered } \\
\text { and Small Parcels (\%) }\end{array}$ & \multicolumn{2}{c|}{$\begin{array}{c}\text { Timing Problem } \\
\text { of Combine } \\
\text { Harvester (\%) }\end{array}$} & \multicolumn{2}{c|}{$\begin{array}{c}\text { FRS Limitation } \\
\text { Problem (\%) }\end{array}$} & \multicolumn{2}{c|}{$\begin{array}{c}\text { Effect of Sunday } \\
\text { Holiday of TMO (\%) }\end{array}$} \\
\cline { 2 - 9 } & Yes & No & Yes & No & Yes & No & Effected & Not effected \\
\hline Small & 33 & 67 & 33 & 67 & 36 & 64 & 33 & 67 \\
\hline Medium & 58 & 42 & 54 & 44 & 65 & 35 & 50 & 50 \\
\hline Large & 14 & 86 & 21 & 79 & 57 & 43 & 21 & 79 \\
\hline Average & 40 & 60 & 40 & 60 & 55 & 45 & 38 & 62 \\
\hline
\end{tabular}


Table 12 - Type of Transportation Vehicle.

\begin{tabular}{|l|c|c|c|}
\hline \multirow{2}{*}{$\begin{array}{c}\text { Size of } \\
\text { Enterprise }\end{array}$} & \multicolumn{3}{|c|}{ Type of Transportation Vehicle (\%) } \\
\cline { 2 - 4 } & Tractor & Truck & Total \\
\hline Small & 25 & 75 & 100 \\
\hline Medium & 17 & 93 & 100 \\
\hline Large & 32 & 68 & 100 \\
\hline Average & 23 & 79 & 100 \\
\hline
\end{tabular}

sidering other transportation in the region; also it is seen that transporters who have alternative transportation opportunity increase transportation fees two times more than normal seasons.

Producers generally state that they didn't have problems in selling their products to TMO, they prefer TMO because it is reliable and its prices are favorable, TMO is a traditional market, but they do not need to sell their products to tradesmen when market conditions were more favorable.

Although there are some producers expressing that they await their turn in the appointment system, they see whether the appointment system will be successful or not.
3.1. Factors determining the Effectiveness of Appointment System: a Factor Analysis Results

The high correlation between variables indicates the suitability of data for factor analysis. The calculated Chi-squared value of the main factors that are effective on the procurement under Appointment System for Barlett's test of Sphericity is 324,180 which is significant at 1 percent level (p:0,000). KMO ratio compares observation and partial correlation coefficient, that indicate variables affect procurement under appointment system is found as more than $0,50(0,636)$ and 17 factors effective on procurement under appointment system is reduced into 5 main factors explaining $78.9 \%$ of the variation (Table 13).

The first factor (F1) determined as effective on procurement by appointment system according to factor analysis is the Sunday holiday of TMO, difficulties in finding combine harvester, scattered and small parcels and FRS limitation. The second factor (F2) is the size of enterprises. Age and education level is the third factor (F3) for adaptation to the appointment system. The Fourth factor (F4)

Table 13 - Factor and Variable Load related to Procurement under the Appointment System and Factor Analysis Results.

\begin{tabular}{|l|c|c|c|c|c|}
\hline \multirow{2}{*}{ Variables } & \multicolumn{5}{|c|}{ Factors } \\
\cline { 2 - 6 } & 1 & 2 & 3 & 4 & 5 \\
\hline Age & $-0,354$ & 0,248 & 0,64 & $-0,063$ & 0,284 \\
\hline Education Level & 0,125 & $-0,19$ & $-0,701$ & $-0,343$ & 0,02 \\
\hline Size of Family & $-0,565$ & 0,405 & $-0,214$ & 0,247 & $-0,339$ \\
\hline Experience & $-0,486$ & 0,293 & 0,702 & $-0,108$ & 0,126 \\
\hline Total Land & 0,115 & 0,916 & $-0,271$ & $-0,04$ & 0,117 \\
\hline Number of Parcels & 0,203 & 0,817 & $-0,374$ & 0,021 & $-0,044$ \\
\hline Wheat Area & $-0,189$ & 0,688 & 0,052 & $-0,142$ & 0,383 \\
\hline Credit Usage & 0,065 & 0,295 & 0,199 & 0,417 & $-0,649$ \\
\hline Determination of Selling Price & $-0,007$ & $-0,169$ & $-0,498$ & 0,488 & 0,509 \\
\hline Resource for Learning Price & 0,303 & $-0,062$ & 0,211 & 0,759 & 0,263 \\
\hline Bringing Combine Harvester in Small Land & 0,873 & 0,268 & 0,209 & $-0,118$ & $-0,05$ \\
\hline FRS Limitation Problem & 0,782 & $-0,261$ & 0,369 & $-0,118$ & 0,004 \\
\hline Problem in Timing of Combine Harvester & 0,91 & 0,149 & 0,066 & $-0,012$ & 0,03 \\
\hline Sunday Holiday of TMO & 0,886 & 0,198 & 0,045 & 0,038 & 0,016 \\
\hline
\end{tabular}

KMO Statistics 0,636

Bartlet Sphericity Test [Chi-Squared: 324,180] (P: 0,000) 
is the knowledge of the producer on the price at which producer sell the product and the institution or tradesmen to whom the producer sell the product. The producer makes a research on price after harvesting the product and they determine to whom they will sell their product according to their loan situation and offered price (F5). If the producers do not get a loan and do not need to receive transportation fee immediately, they prefer to sell their product to tradesmen, otherwise, they sell to TMO. According to the results of the study "Agricultural Policies Applied for Wheat in Turkey and Problems of Wheat Producers in Thrace Region" as carried out by (Konyalı and Gaytanc1oğlu, 2007) by using factor analysis, the most important problems of producers are «training of farmers, increase in consumption of farinaceous food, scattered land, violate cropping system and low productivity».

During the procurement process, tradesmen pay an amount of money in cash to the producer to ensure them to meet their emergent expenditures (harvest, transportation and food) and the needs such as harvest and family needs. A similar application for procurements realized by TMO would be beneficial. Some of the transporters and combine harvester operators wait for the money for their services rendered until producers get their payment from TMO, but some of them, especially who come from other cities, request their payment immediately. Payments' being realized immediately or later directly bring about difficulties in finding combine harvester and truck. Also, cash payment would make it easier to bring combine harvester to small parcels.

\section{Conclusion and Recommendations}

Cereals, particularly wheat, make a very vital contribution to the national economy and rural livelihood of many families. Wheat production has increased in years, depending on an increase in productivity when compared to increasing population. It is possible to mention the positive effects of agricultural supports and intervention procurements realized by TMO in terms of both consumer and producer. The TMO is still is an important actor in the marketing process, since 2013 Appointment System has been implemented and the main aims of this system are to shorten the 4-5 day waiting periods of producers while delivering their product which was the case in previous years, so as to prevent long queues in front of TMO procurement points, to prevent the trouble that can occur between producers and transportation fees caused by waiting process. On the other hand, another aim is to prevent the negative effects of the shortness of harvest season and concentration of supply in a certain period on market price.

Under the Appointment System, harvest problems such as weekend holiday of the TMO and difficulties in providing combine harvester, structural problems such as scattered and small parcels and FRS limitation, also socio-economic characteristics of entrepreneurs, financial structure and price are effective factors in the marketing of wheat.

It is seen that Appointment System for Procurement is partially successful, it makes the marketing process easier, decreases costs and shortens harvest period. Flexibility in the appointment system and paying a certain amount to the producer immediately during procurement, also ensuring TMO to procure products in weekends will minimize problems such as determination of harvest period, provision of a combine harvester and transportation vehicle etc. Furthermore, these will make an adaptation of the producers easier and ensure the realization of the envisaged benifits from the system.

\section{References}

Akdemir Ş., 1994. Socio-economical Analysis and Classification of Agricultural Enterprises in Down-Seyhan Plain, Adana, Çukurova University Faculty of Agriculture Periodical, 10(4).

Akgül A., Çevik O., 2003. Statistical Analysis Techniques, SPSS Operation Management Applications, Ankara: Emek Offset.

Bayaner A., 2013, Agriculture in Turkey- Expectations and Developments, Agricultural Economy and Policy Development Institute, n. 224.

Demirbaş N., Atış E., 2005. Examination of Food Security Problems in Agriculture in Turkey in Terms of Wheat, Ege University Faculty of Agriculture Periodical, 2005, 42(1): 179-190.

Karabak S., Taşçı R., Acar O., Bozdemir Ç., 2013. Marketing Behaviors of Wheat Producers in Ankara, Si- 
vas and Yozgat Provinces, $18^{\text {th }}$ National Marketing Congress Proceedings - Contribution of Global Marketing to Internationalization of Local Economies, Kars, Kafkas University Faculty of Economics and Administrative Sciences, 19-22 June 2013.

Kizilaslan H., 2004. Wheat Production in the World and Turkey and Comparison of Applied Policies, GOU. Tokat, Faculty of Agriculture Periodical, 2004, 21 (2), 23-38.

Konyalı S., Gaytancıoğlu O., 2007. Agricultural Policies Applied in Turkey for Wheat and Problems of Wheat Producers in Thrace Region, Tekirdağ, Tekirda $\breve{g}$ Faculty of Agriculture Periodical, 4(3): 249-259.

KB, 2014, Specialized Commission Report on Food Product and Safety, Ministry of Development, Ankara.

Küçükçongar M., Kan F., Özdemir F., 2014. Use of No-tillage System in Wheat Cultivation and Determination of Views of Farmers: Konya Sample, Bahri Dağdaş Crop Research Periodical, Konya, Bahri Dağdaş International Agricultural Research Institute Directorate.
KTB, 2014. Analysis of Structural Features in Agricultural Industry and Modeling Competition Strategies, Karatay-Konya, Konya Commodity Exchange Fevzi Çakmak Mahallesi Bayraktar Sokak, n. 1.

Süzer S., 2015. Measures to be Taken for Decreasing Grain Loss in Wheat Harvest, Edirne, Trakya Agricultural Research Institute Directorate.

Tatlidil H., 2002. Applied Multi-Variable Statistical Analysis, Ankara, Akademi Matbaası, 167.

TÜIK, 2015. Turkish Statistical Institute, Ankara.

TMO, 2014. Turkish Grain Board, Ankara.

Y1lmaz E.R., 2010, Economic Analysis of Agricultural Enterprises Dealing with Wheat Cultivation in Merkez Country of Kırşehir Province, Tokat, Gaziosmanpaşa University Institute of Science, Department of Agricultural Economy.

Yıldız S., Pazarcık Y., Taşkıran E., Deniz A., Beyazit N., 2013. A Research on Administrative, Production, Economic and Marketing Problems of Wheat Producers in Kars Province, Kars, Institute of Social Sciences Periodical, 12, Autumn 2013: 73-95. 